\title{
Evaluación de un método de doble centrifugación en tubo para concentrar plaquetas bovinas: estudio celular
}

\author{
Evaluation of a double centrifugation tube method for concentrating \\ bovine platelets: cellular study \\ C López ${ }^{\text {a, b }}$, CE Giraldoa, JU Carmona ${ }^{a^{*}}$ \\ ${ }^{a}$ Grupo de Investigación Terapia Regenerativa, Departamento de Salud Animal, \\ Universidad de Caldas, Manizales, Colombia. \\ bBecaria COLCIENCIAS “Generación Bicentenario”, Programa de Doctorado en Ciencias Biomédicas, \\ Universidad de Caldas, Manizales, Caldas, Colombia.
}

\begin{abstract}
SUMMARY
The aim of this study was to evaluate a double centrifugation tube method for concentrating bovine platelets. Whole blood samples were collected from clinically normal Holstein cows and processed using a double centrifugation tube method to obtain platelet rich plasma (PRP). PRP and whole blood were analysed by a volumetric impedance system for hemogram and additional platelet parameters (mean platelet volume (MPV) and platelet distribution width (PDW). Platelet concentrations for PRP were 229\% higher in comparison with platelet concentration for whole blood samples. There were positive significant correlations between platelet and lymphocyte counts $(\rho=0.81 ; \mathrm{P}=0.0001)$, platelet and leukocyte counts $(\rho=0.75 ; \mathrm{P}=0.0001)$ and, a significant negative correlation between platelet count and PDW $(\rho=-0.72 ; \mathrm{P}=0.0001)$. In conclusion, the double centrifugation tube method evaluated in this study is a reliable method for producing bovine PRP.
\end{abstract}

Palabras clave: bovino, concentrado autólogo plaquetas, medicina regenerativa, método del tubo.

Key words: bovine, autologous platelet concentrates, regenerative medicine, tube method.

\section{INTRODUCCIÓN}

El plasma rico en plaquetas (PRP) representa un reservorio importante de diversos factores de crecimiento (GFs), entre los que se destacan el factor de crecimiento transformante beta isoforma 1 (TGF- $\beta_{1}$ ), factor de crecimiento parecido a la insulina isoforma tipo I (IGF-I), factor de crecimiento derivado de las plaquetas (PDGF) (Eppley y col 2004, Argüelles y col 2006, Carmona y col 2008) y otras proteínas que disminuyen la inflamación y aceleran la reparación de tejidos traumatizados o afectados por enfermedades crónicas (Fréchette y col 2005). En medicina humana el PRP inicialmente se empleó como coadyuvante quirúrgico en reconstrucciones alvéolomaxilares (Marx y col 1998) y su uso se ha extendido a la cirugía plástica y cirugía ortopédica. En personas, este biofármaco también ha sido empleado como tratamiento de lesiones tendinosas, úlceras gástricas, úlceras cutáneas crónicas y úlceras corneales, entre otras aplicaciones clínicas (Roukis y col 2006).

En medicina veterinaria se ha reportado la utilización clínica de PRP (también conocido como concentrado autólogo de plaquetas -APCs-) en equinos como tratamiento de afecciones locomotoras crónicas (Carmona y col 2009a , Carmona y col 2009 ), traumatismos (López y col 2010) y heridas de las extremidades (Carmona y col

Aceptado: 07.12.2011.

* Calle 65 N²6-10, Manizales, Colombia; carmona@ucaldas.edu.co
2011). En caninos se ha informado el uso experimental de esta sustancia con resultados controversiales. Sin embargo, su uso clínico en esta especie se está popularizando como coadyuvante quirúrgico en cirugía ortopédica de rodilla (Silva y col 2011 ). A pesar del uso creciente del PRP en medicina equina (Carmona y col 2011), según lo revisado por los autores, no existen estudios sobre la biología básica o la aplicación clínica del PRP en bovinos. Hasta el momento, algunos trabajos publicados sobre la obtención de PRP en bovinos están relacionados con investigaciones sobre endotoxemia (Dohmen y col 2000, Wittek y col 2004) o evaluación de defectos de la coagulación (Searcy y col 1990) y no se han descrito métodos para obtener PRP con finalidades terapéuticas en esta especie.

El objetivo fundamental de la presente investigación fue estandarizar un método manual de doble centrifugación en tubo para concentrar plaquetas bovinas. Al igual que otros mamíferos en los que el PRP ha sido empleado clínica o experimentalmente (Roukis y col 2006, Carmona y col 2011), existe un amplio número de posibilidades en los que esta sustancia podría ser empleada de manera terapéutica en bovinos, tales como afecciones crónicas del aparato locomotor, traumatismos agudos (secundarios o no a procedimientos quirúrgicos) (Heppelmann y col 2009) e incluso infecciones localizadas, como la mastitis.

La hipótesis de este estudio fue que las plaquetas de bovino podrían ser concentradas mediante la recolección de sangre entera en tubos con citrato de sodio al usar un procedimiento manual de doble centrifugación. 


\section{MATERIAL Y MÉTODOS}

Este estudio fue aprobado por el comité de ética para experimentación con animales de la institución.

\section{ANIMALES}

Fueron utilizadas doce (12) vacas de raza Holstein con una edad mediana de 5 años (rango: 2,5-10 años). Las vacas fueron clínicamente sanas al momento de la recolección de la sangre. Estas fueron evaluadas mediante examen físico, hemograma, pruebas de química clínica, examen coprológico y extendidos de sangre periférica para descartar la presencia de babesia y anaplasma. Las vacas pertenecían a una misma granja, por lo que las condiciones de alimentación y manejo de los animales fueron similares.

Las vacas tenían una condición corporal mediana de 3,5/5 (rango: 3-4/5). El número mediano de partos por vaca fue de 3 (rango 1-7 partos). Seis de las doce vacas se encontraban en gestación y estas presentaban un tiempo de gestación mediana de 4,5 meses (rango: 2,5-6 meses). El número mediano de días de lactancia fue de 181 (rango: 45-630 días) y la producción promedio de leche fue de $27,5 \mathrm{~L}( \pm 9,8 \mathrm{~L})$.

\section{RECOLECCIÓN DE LA SANGRE}

Para obtener la sangre, un catéter intravenoso $14 \mathrm{G}$ de $6 \mathrm{~cm}$ (NIPRO14GX2", Nipro, San Pablo, Brasil) fue fijado con suturas en una de las venas yugulares de cada vaca. Los catéteres fueron cerrados con un tapón libre de látex (IN-Stopper, B Braun, Melsungen, Alemania) y lavados con $5 \mathrm{~mL}$ de suero heparinizado. La sangre fue obtenida mediante el acople de un catéter mariposa $21 \mathrm{G}$ (Blood Collection Set, BD Vacutainer, New Jersey, EE.UU.) al tapón. La sangre de cada vaca fue depositada en tubos de $4,5 \mathrm{~mL}$ con $3,2 \%$ de citrato de sodio (w/v) (BD Vacutainer, New Jersey, EE.UU.). El primer tubo recolectado fue descartado, para evitar el efecto dilucional o bioquímico del suero heparinizado. Las muestras de sangre fueron mantenidas y transportadas al laboratorio en una nevera con hielo y procesadas una hora después de haber sido obtenidas.

\section{MÉTODO DE CENTRIFUGADO SIMPLE EN TUBO}

La sangre fue centrifugada (Hettich Rotofix 32, Tuttlingen, Alemania) a 720 x g por 5 minutos. La centrifugación permitió separar la sangre en tres interfases: eritrocitos, capa leucocitaria (buffy coat) y plasma. El plasma fue arbitrariamente dividido en dos fracciones, fracción plasmática A (PFA) y fracción plasmática B (PFB). La PFA fue considerada como el $50 \%$ del plasma más cercano a la capa leucocitaria. La PFB fue clasificada como el 50\% de la fracción plasmática inmediatamente superior a la PFA (figura 1A). La PFA fue obtenida con el estilete de un catéter intravenoso No 14G de $6 \mathrm{~cm}$ (NIPRO14GX2",
Nipro, San Pablo, Brasil), acoplado a una jeringa de plástico de $20 \mathrm{ml}$. En total se obtuvieron $21 \mathrm{~mL}$ de PFA por vaca. Una alícuota de $1 \mathrm{~mL}$ de esta fracción fue empleada para conteo hematológico automatizado.

\section{MÉTODO DE CENTRIFUGADO DOBLE EN TUBO}

La PFA (20 mL) fue depositada en dos tubos estériles de plástico PET sin aditivo (Vacuette, Greiner Bio-One, Kremsmünster, Austria). Los tubos fueron centrifugados a $720 \mathrm{x}$ g por 5 minutos. El PRP fue obtenido al eliminar el 75\% (7,5 mL) de la fracción plasmática superior de los tubos (figura 1B). El PRP fue homogeneizado suavemente y considerado para el análisis hematológico del estudio.

\section{ANÁLISIS HEMATOLÓGICO}

Se realizó un hemograma completo por triplicado a cada muestra (sangre citratada, PFA y PRP) con un sistema hematológico de impedancia volumétrica (Celltac- $\alpha$ MEK 6450, Nihon Kodhen, Japón). Los parámetros hematológicos evaluados fueron: conteo de plaquetas $/ \mu \mathrm{L}(\mathrm{PLT} / \mu \mathrm{L})$ y parámetros plaquetarios asociados, volumen plaquetario medio (MPV) y ancho de distribución plaquetaria (PDW). Conteo de leucocitos $/ \mu \mathrm{L}(\mathrm{WBC} / \mu \mathrm{L})$, valores relativos (\%)

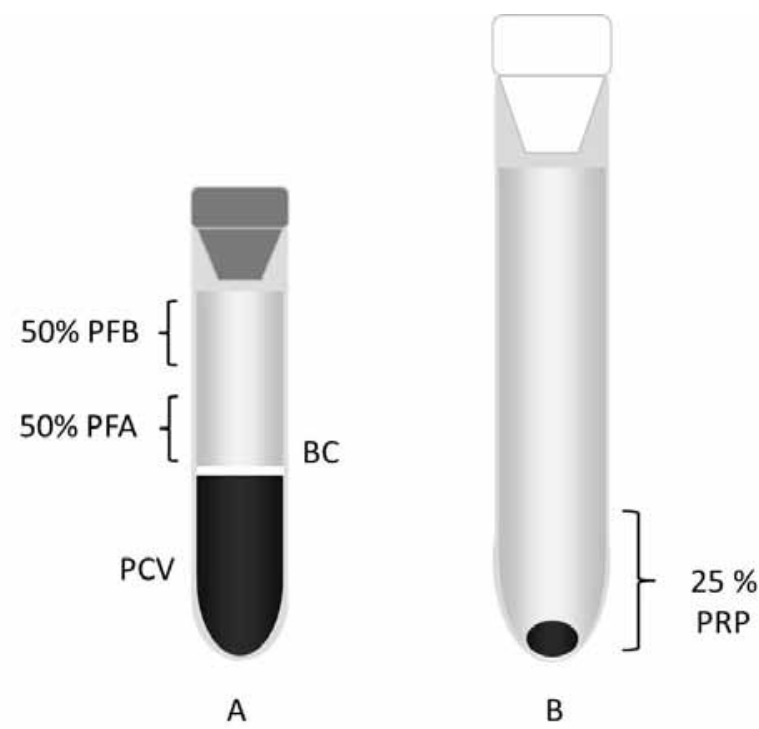

Figura 1. El tubo A (con citrato de sodio) representa la primera fracción de plasma 50\% (FPA) obtenida durante el primer centrifugado a $120 \mathrm{~g}$ por $5 \mathrm{~min}$. El tubo B (sin aditivo) representa la fracción plasmática de la que se obtiene el plasma rico en plaquetas (PRP) después de centrifugar la FPA a $240 \mathrm{~g}$ por $5 \mathrm{~min}$. $\mathrm{FPB}=$ Fracción plasmática $\mathrm{B}$. PCV = paquete de volumen celular. BC: capa leucocitaria.

The tube A (with sodium citrate) represents the first 50\% plasma fraction (FPA) obtained at the first spun at $120 \mathrm{~g}$ for $5 \mathrm{~min}$. The tube B (without additive) represents the plasma fraction where platelet rich plasma (PRP) is obtained after the second spun at $240 \mathrm{~g}$ for $5 \mathrm{~min}$. $\mathrm{FPB}=$ Plasmatic fraction $\mathrm{B} . \mathrm{PCV}=$ Packed cellular volume $\mathrm{BC}=$ Buffy coat. 
y absolutos (células/ $\mu \mathrm{L}$ ) de linfocitos (LYM), monocitos (MON), eosinófilos (EOS), neutrófilos y basófilos (GRA) $\mathrm{y}$ volumen de paquete celular (PCV). El valor promedio de los datos hematológicos fue usado en el análisis estadístico.

\section{ANÁLISIS ESTADÍSTICO}

Los datos fueron presentados en función de la prueba de normalidad (prueba de Shaphiro-Wilk). Las variables que exhibieron normalidad (S-W: $\mathrm{P}>0,05$ ) son presentadas como promedio (desviación estándar). Las variables que presentaron distribución no paramétrica $(\mathrm{S}-\mathrm{W}: \mathrm{P}>0,05)$ son presentadas como mediana (rango intercuartílico). Las variables paramétricas fueron evaluadas con un ANOVA de una vía. Las pruebas post-hoc realizadas dependieron de la prueba de homogeneidad de varianza (prueba de Levene: $\mathrm{P}>0,05$ ). Los datos que presentaron homogeneidad de varianza fueron analizados mediante una prueba de Tukey y los que no, con una prueba de Games-Howell. Las variables no paramétricas fueron analizadas mediante una prueba de Kruskal-Wallis y como prueba post-hoc se emplearon comparaciones pareadas de U de Mann-Whitney. Los valores de las variables de cada grupo hematológico fueron correlacionadas de manera general (entre todos los grupos hematológicos) y específica (dentro de cada grupo hematológico) mediante una prueba de Spearman $(\rho)$ con los factores: edad, condición corporal (I-V/V), número de partos, días de lactancia, lactancia promedio al momento de la toma de sangre, estado reproductivo (gestante o no) y días de gestación. Un valor de $\mathrm{P}<0,05$ fue aceptado como significativo para todas las pruebas.

La eficiencia de colección de plaquetas se determinó mediante la fórmula de Weibrich y col (2003): (volumen de (PFA) PRP x recuento de plaquetas en (PFA) PRP/ volumen de sangre entera $x$ recuento de plaquetas en sangre entera) x 100 .

\section{RESULTADOS}

Los conteos de PLT/ $\mu \mathrm{L}$ difirieron significativamente $(\mathrm{P}<0,01)$ entre cada muestra hematológica (sangre entera, PFA y PRP). Los valores del MPV fueron similares entre cada muestra hematológica. Sin embargo, el PDW fue significativamente superior para la PFA respecto a la sangre entera y el PRP (cuadro 1). Los conteos de $\mathrm{WBC} / \mu \mathrm{L}$, valores absolutos y relativos de linfocitos, relativos de monocitos y granulocitos y $\mathrm{PCV}$ presentaron diferencias estadísticamente significativas $(P<0,05)$ entre cada muestra hematológica. Los valores absolutos de los monocitos fueron similares entre sangre entera y PFA, pero ambos difirieron del PRP. Los valores absolutos y relativos de los eosinófilos fueron iguales entre la PFA y el PRP, pero difirieron significativamente de los mismos valores en sangre entera (cuadro 2).

El análisis general de correlaciones demostró correlación alta entre WBC/ $\mu \mathrm{L}$ y $\mathrm{LY} / \mu \mathrm{L}(\rho=0,94 ; \mathrm{P}=0,0001)$, correlaciones moderadas entre $\mathrm{PLT} / \mu \mathrm{L}$ y $\mathrm{WBC} / \mu \mathrm{L}(\rho=0,75$;
$\mathrm{P}=0,0001)$ y entre $\mathrm{PLT} / \mu \mathrm{L}$ y $\mathrm{LY} / \mu \mathrm{L}(\rho=0,81 ; \mathrm{P}=0,0001)$ y correlaciones bajas entre PLT/ $\mu \mathrm{L}$ y $\mathrm{MO} / \mu \mathrm{L}(\rho=0,62$; $\mathrm{P}=0,0001)$. Cuando los valores de las variables hematológicas de la sangre entera y el PRP fueron correlacionados, se observó correlación moderada entre PLT $/ \mu \mathrm{L}$ y LY/ $\mu \mathrm{L}$ ( $\rho=0,70 ; \mathrm{P}=0,0001)$ y correlación baja negativa entre $\mathrm{PLT} / \mu \mathrm{L}$ y EO/ $\mu \mathrm{L}(\rho=-0,64 ; \mathrm{P}=0,0001)$. Al correlacionar los resultados de las variables hematológicas entre la PFA y PRP se halló correlación alta entre PLT/ $\mu \mathrm{L}$ y WBC/ $\mu \mathrm{L}$ $(\rho=0,81 ; \mathrm{P}=0,0001)$ y entre $\mathrm{PLT} / \mu \mathrm{L}$ y LY $/ \mu \mathrm{L}(\rho=0,79$; $\mathrm{P}=0,0001)$. También se encontró una correlación negativa moderada entre PLT $/ \mu L$ y PDW\% $(\rho=-0,72 ; \mathrm{P}=0,0001)$. Los factores edad, condición corporal, número de partos, días de lactancia, lactancia promedio al momento de la toma de sangre, estado reproductivo (gestante o no) y días de gestación no se correlacionaron con las variables hematológicas de manera general o por separado. La eficiencia de colección de plaquetas para la PFA fue de $25,4 \%$ y para el PRP fue de $19,1 \%$.

\section{DISCUSIÓN}

El primer método manual de centrifugación única en tubo para concentrar plaquetas en seres humanos fue descrito por Anitua (1999). Posteriormente, se describió un método manual de doble centrifugación en tubo para obtener concentrados de plaquetas en caballos (Argüelles y col 2006, Carmona y col 2008) y recientemente se han descrito dos métodos de centrifugación simple en tubo con el mismo objetivo en caninos (Silva y col $2011^{c}$ ) y felinos (Silva y col 2011 ). El análisis de estas investigaciones permite apreciar que el tamaño y peso tanto de las plaquetas como de los leucocitos determinan el protocolo a utilizar para poder concentrar plaquetas de manera efectiva en cada especie.

Se han descrito tres sistemas generales para producir PRP con finalidades terapéuticas en seres humanos, caballos y perros (Eppley y col 2004, Thoesen y col 2006, Carmona y col 2011, Silva y col 2011 b): 1) aféresis (sistema automatizado), 2) sistemas semiautomatizados de "buffy coat (BC)" y 3) sistemas (métodos) manuales de centrifugación simple y doble en tubo (Anitua 1999, Dohan Ehrenfest y col 2009). No obstante, los métodos manuales, como el evaluado en el presente estudio, llaman la atención de clínicos e investigadores, ya que se obtienen productos que pueden entregar una opción terapéutica efectiva y de bajo costo para tratar traumatismos y afecciones crónicas músculo-esqueléticas (entre otras) en estas especies animales (Roukis y col 2006, Carmona y col 2011).

Según lo revisado, esta es la primera investigación en la que se reporta un método para obtener PRP con potencial terapéutico en bovinos. Los resultados del presente estudio demuestran que el PRP obtenido puede concentrar un 229\% de plaquetas respecto al valor basal de estos fragmentos citoplasmáticos en sangre entera. Este valor es alto en comparación con la concentración de plaquetas (172\%) 
Cuadro 1. Valores promedio (desviación estándar) del conteo de plaquetas y variables plaquetarias asociadas en los diferentes grupos hematológicos del estudio.

Mean (standard deviation) values for platelet count and platelet related variables in each hematological group of the study.

\begin{tabular}{lcccccc}
\hline Variable & \multicolumn{2}{c}{ Sangre entera } & \multicolumn{2}{c}{ Fracción plasmática A } & \multicolumn{2}{c}{ Plasma rico en plaquetas } \\
\hline Plaquetas x $10^{3} / \mu \mathrm{L}$ & 384 & $(68,9)$ & 293,6 & $(81,1)^{\mathrm{a}}$ & 882 & $(197,6)^{\mathrm{b}}$ \\
MPV fL & 3,03 & $(0,22)$ & 3,02 & $(0,27)$ & 3,12 & $(0,26)$ \\
PDW \% & 16,4 & $(0,6)^{\mathrm{a}}$ & 18,1 & $(0,9)^{\mathrm{b}}$ & 16,7 & $(0,6)^{\mathrm{a}}$ \\
\hline
\end{tabular}

MPV: Volumen plaquetario medio. PDW: Ancho de distribución plaquetaria. a-b Variable significativamente diferente $(\mathrm{P}<0,01)$ entre cada grupo hematológico en la misma fila.

MPV: Mean platelet volume. PDW: platelet distribution width. a-b Variable significantly different $(\mathrm{P}<0.01)$ between each hematological group for the same arrow.

Cuadro 2. Valores medianos (rango intercuartílico) de las variables evaluadas en los diferentes grupos hematológicos del estudio. Median (interquartile range) values for the variables evaluated for the hematologic groups of the study.

\begin{tabular}{|c|c|c|c|c|c|c|}
\hline \multirow{2}{*}{$\begin{array}{l}\text { Variable } \\
\text { Leucocitos } \times 10^{3} / \mu \mathrm{L}^{*}\end{array}$} & \multicolumn{2}{|c|}{ Sangre entera } & \multicolumn{2}{|c|}{ Fracción plasmática A } & \multicolumn{2}{|c|}{ Plasma rico en plaquetas } \\
\hline & 9,0 & $(2,2)$ & 3,3 & $(2,5)^{\mathrm{a}}$ & 4,2 & $(9,7)^{\mathrm{b}}$ \\
\hline Linfocitos x $10^{3} / \mu \mathrm{L}$ ) & 5,2 & $(1,5)$ & 2,4 & $(1,5)^{\mathrm{a}}$ & 8,8 & $(4,7)^{\mathrm{b}}$ \\
\hline Linfocitos $\% *$ & 61,7 & $(11,2)$ & 86,3 & $(8,8)^{\mathrm{a}}$ & 80,2 & $(7,3)^{\mathrm{a}}$ \\
\hline Monocitos x $10^{3} / \mu \mathrm{L}$ & 0,05 & $(0,1)^{\mathrm{a}}$ & 0,0 & $(0,08)^{\mathrm{a}}$ & 0,2 & $(0,2)^{\mathrm{b}}$ \\
\hline Monocitos \% & 0,5 & $(1,0)$ & 0,0 & $(1,6)^{\mathrm{a}}$ & 1,5 & $(2,2)^{\mathrm{b}}$ \\
\hline Granulocitos $\times 10^{3} / \mu \mathrm{L}$ & 2,4 & $(1,6)^{\mathrm{a}}$ & 0,3 & $(0,5)^{b}$ & 2,3 & $(2,6)^{\mathrm{a}}$ \\
\hline Granulocitos \% & 27,6 & $(13,7)$ & 10,4 & $(11,2)^{\mathrm{a}}$ & 18,6 & $(12,7)^{\mathrm{b}}$ \\
\hline Eosinófilos x $10^{3} / \mu \mathrm{L}$ & 0,7 & $(0,6)^{\mathrm{a}}$ & 0,0 & $(0,0)^{\mathrm{b}}$ & 0,0 & $(0,2)^{\mathrm{b}}$ \\
\hline Eosinófilos \% & 7,1 & $(6,8)^{\mathrm{a}}$ & 0,0 & $(0,5)^{b}$ & 0,0 & $(0,5)^{\mathrm{b}}$ \\
\hline Volumen de paquete celular $\%$ & 28,8 & $(3,0)$ & 0,35 & $(0,3)^{\mathrm{a}}$ & 1,4 & $(1,0)^{\mathrm{b}}$ \\
\hline
\end{tabular}

* Los datos son presentados como media (desviación estándar). a-b: Variable significativamente diferente $(\mathrm{P}<0,05)$ entre cada grupo hematológico en la misma fila.

* Data are presented as mean (standard deviation). a-b: Variable significantly different $(\mathrm{P}<0.05)$ between each hematological group for the same arrow.

obtenida mediante una técnica de doble centrifugación en caballos (Argüelles y col 2006). En este trabajo se apreciaron valores relativamente bajos del MPV en sangre entera y en las fracciones plasmáticas evaluadas, PFA y PRP. De hecho estos valores no difirieron estadísticamente entre las muestras hematológicas estudiadas. Los resultados observados en el MPV indican escasa o nula activación plaquetaria del PRP bovino obtenido mediante esta técnica. Sin embargo, el PDW fue significativamente más alto en la PFA en comparación con la sangre entera y el PRP. Este hecho se pudo deber a ligeros cambios (no significativos) del MPV (activación) de las plaquetas al ser centrifugadas con los demás componentes sanguíneos de la sangre entera, particularmente eritrocitos. El PDW es un índice plaquetario relacionado con el tamaño de las plaquetas y está estrechamente asociado con el MPV. Cuando el MPV cambia debido a activación plaquetaria, el PDW incrementa (Lee y Kim 2010). Sin embargo, cuando las plaquetas son centrifugadas a bajas revoluciones sin eritrocitos el MPV tiende a disminuir quizás porque cuando las plaquetas están bajo el efecto de anticoagulantes, tales como el citrato de sodio, pueden revertir de manera fisiológica su proceso de activación. Este fenómeno se conoce como reacción de liberación reversible (Argüelles y col 2006).

Con la técnica descrita se logró concentrar 1,57 veces más la cantidad de leucocitos respecto al recuento basal de estas células en sangre entera. En caballos, mediante una técnica parecida se concentraron los WBC 1,18 veces más respecto a los valores basales de estas células en sangre entera (Argüelles y col 2006). Por el contrario, al realizar procedimientos de centrifugado simple en perros y gatos, la concentración de WBC fue menor en las fracciones terapéuticas evaluadas $(0,57$ y 0,36 veces menos, respectivamente) en comparación con los recuentos de WBC en la sangre entera de estas dos especies animales (Silva y

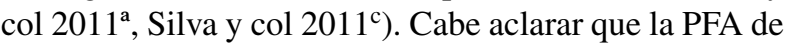
las vacas de este estudio presentó concentraciones leucocitarias bajas ( 0,64 veces menos) respecto a los recuentos basales de la sangre entera (cuadro 2).

Este comportamiento también fue comparable en concentrados de plaquetas de caballos obtenidos durante la primera centrifugación. En tal sentido el concentrado 
de plaquetas A (PC-A), similar a la PFA de las vacas de este estudio, concentró WBC 0,46 veces menos que el recuento basal de estas mismas células en sangre entera (Argüelles y col 2006). Como se puede apreciar, con los métodos manuales (tubo) en general se puede lograr una concentración adecuada de plaquetas (x2) en pequeños carnívoros domésticos respecto al recuento basal en sangre entera con una concentración baja de WBC. Sin embargo, para lograr una concentración importante de plaquetas en caballos y vacas mediante métodos manuales es necesario recentrifugar la PFA (PC-A). Mediante este procedimiento se obtienen concentrados con conteos superiores de plaquetas (x1,7 en caballos a x2,36 en vacas), pero la concentración de WBC también aumenta (Argüelles y col 2006).

Sobre este último aspecto se debe considerar la interrogante del papel (benéfico o perjudicial) de los leucocitos presentes en el PRP, la cual, hasta el momento, aún no ha sido resuelta (Carmona y col 2011). Además, se debe pensar que aunque con los métodos semiautomatizados se logra concentrar cantidades superiores de plaquetas en comparación con los métodos manuales, también la concentración de WBC aumenta dramáticamente (Dohan Ehrenfest y col 2009, Carmona y col 2011). Queda entonces pendiente saber si los leucocitos son necesarios en el PRP y en qué concentración; además, si conteos leucocitarios demasiado altos pueden ser considerados como contaminantes del PRP; datos recientes en los que se evaluó el efecto antibacteriano de los concentrados de plaquetas de caballos contra Staphylococcus aurus resistente a la meticilina demostraron que los concentrados de plaquetas pobres en leucocitos tenían un efecto igual o incluso superior a los concentrados de plaquetas con mayor recuento leucocitario (Álvarez y col 2011). Aunque no comparables, desde el punto de vista regenerativo, en este estudio se observó que quizás los leucocitos no sean del todo necesarios para la actividad bactericida in vitro del PRP. Se mantiene la hipótesis de que quizás los leucocitos no sean necesarios para el efecto regenerativo mediado por las plaquetas.

El cambio de la proporción de las subpoblaciones leucocitarias es bastante llamativo cuando se evalúan fracciones de concentrados de plaquetas (PRP) obtenidos mediante el método del tubo en perros (Silva y col 2011 ${ }^{\mathrm{c}}$ ), gatos (Silva y col 2011 a), caballos (Argüelles y col 2006) y vacas. Los concentrados de plaquetas obtenidos mediante el método del tubo en gatos presentan un incremento absoluto y porcentual de linfocitos (Silva y col 2011 ${ }^{\mathrm{a}}$ ) y ese mismo fenómeno fue observado en el PRP de las vacas de nuestro estudio. Sin embargo, en caninos y equinos sólo se ha observado un incremento porcentual en la población linfocitaria de los concentrados de plaquetas, respecto al recuento de estas células en la sangre entera. Por otra parte, la población de granulocitos concentrada en el PRP de gatos (Silva y col 2011 a), perros (Silva y col 2011 ) y caballos (Argüelles y col 2006) disminuye significativamente de manera absoluta y relativa en los concentrados de plaquetas. Este hecho también fue observado en el PRP de las vacas de este estudio. No se conoce el significado biológico de la disminución de los granulocitos en los PRP de estas especies animales. Sin embargo, el papel natural de los granulocitos es básicamente pro-inflamatorio y quizás la disminución absoluta y proporcional de estas células en el PRP hagan de este una sustancia con menor poder inflamatorio que otras clases de PRP (producidas por sistemas semiautomáticos) en los que una gran cantidad de granulocitos son concentrados (Dohan Ehrenfest y col 2009). Sin embargo, esto deberá ser probado experimentalmente.

El análisis de las correlaciones permite entrever comportamientos celulares diferentes del PRP bovino frente a los concentrados de plaquetas obtenidos en carnívoros domésticos (Silva y col 2011'a Silva y col 2011') y algo parecido a lo observado en caballos (Argüelles y col 2006). Por ejemplo, en perros y gatos no existió ninguna correlación entre los conteos de plaquetas del PRP y los conteos de WBC y curiosamente se observó una correlación negativa moderada $(-0,70)$ entre los conteos de linfocitos y número de PLT/ $\mu \mathrm{L}$ concentrados en el PRP. Por su parte en el PRP bovino se observó una correlación moderada alta (75\%) entre el conteo de PLT y WBC. Este hecho tuvo un comportamiento parecido en concentrados de plaquetas de caballos obtenidos por doble centrifugación, en los que se apreció una correlación moderada baja entre ambos parámetros (67\%). (Argüelles y col 2006). Sin embargo, la concentración de linfocitos presentó una correlación significativamente alta (80\%) respecto a la concentración de plaquetas en el PRP bovino y este hecho no fue similar en caballos (Argüelles y col 2006).

La correlación negativa moderada $(-0,72)$ observada entre el conteo de plaquetas y el PDW en PRP bovino fue un punto muy importante en este estudio y hasta el momento no se ha descrito ninguna correlación de este tipo en las especies domésticas estudiadas (Argüelles

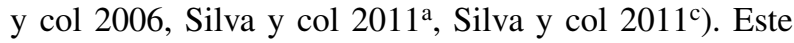
hallazgo permite inferir que si las plaquetas bovinas se activan de manera prematura, el número total de plaquetas concentradas en PRP será menor. Cabe recordar que el PDW en este estudio parece actuar como un indicador de activación plaquetaria prematura, en lugar del MPV (Lee y Kim 2010) y el mensaje principal de este hallazgo estriba en el hecho de obtener la sangre bovina en las mejores condiciones técnicas para producir PRP. Es necesario recordar que quizás lo que menos importa es concentrar grandes cantidades de plaquetas dañadas (activadas irreversiblemente), sino concentrar un adecuado número de las mismas, pero en condiciones fisiológicas óptimas (no activadas), de manera que la reacción de liberación de las mismas sea activada en el momento de la inyección terapéutica (Carmona y col 2011).

Aunque en el presente estudio no se pudieron demostrar correlaciones o diferencias estadísticamente significativas asociadas con las variables hematológicas y los parámetros 
zootécnicos, es posible que sí exista tal diferencia cuando se aumente el tamaño de la muestra por encima de 50 vacas. Sin embargo, un experimento de tal tamaño sería impracticable en nuestro caso.

En el caso específico de los bovinos (Bos taurus) se pudo apreciar que la sangre de esta especie requiere una mayor fuerza de centrifugación (720 g) que las demás especies animales. Tal como sucede en los equinos, son necesarios dos episodios de centrifugación de 5 minutos cada uno y el porcentaje de la fracción terapéutica (PRP) en esta especie representó el $25 \%$ (ubicada en el fondo del tubo) de la PFA centrifugada. Hasta ahora, con la metodología empleada se podría pensar que la especie bovina es la que mayor número de plaquetas concentra por $\mathrm{mL}$, cuando se compara este PRP contra los concentrados de plaquetas obtenidos mediante el método del tubo por centrifugación simple en humanos (Weibrich y col 2005), perros (Silva y col 2011 ${ }^{\mathrm{c}}$ ) y gatos (Silva y col 2011 ) o por doble centrifugación en caballos (Argüelles y col 2006, Carmona y col 2008). Sin embargo, la eficiencia de colección de plaquetas bovinas mediante el método descrito en este artículo fue más alto $(19,1 \%)$ que el método de doble centrifugado descrito en caballos (7,5\%) (Argüelles y col 2006) y más bajo que los métodos de centrifugación simple descritos para perros $(29,9 \%)$ (Silva y col $2011^{\mathrm{c}}$ ) y gatos (50\%) (Silva y col 2011 $\left.{ }^{\mathrm{a}}\right)$.

Se concluye que en este artículo se presenta un método novedoso para concentrar plaquetas en bovinos Bos taurus. El conteo de linfocitos está estrechamente correlacionado con la concentración final de PLT/ $\mu \mathrm{L}$ en PRP. Se deben extremar medidas que eviten la activación prematura de las plaquetas cuando se prepare PRP en bovinos. Esto incluye aspectos como adecuada sujeción de los animales, utilización de catéter intravenoso y utilización de anticoagulantes adecuados. En este estudio, la utilización de citrato de sodio pareció ser adecuada. Sin embargo, es necesario efectuar una investigación comparativa de varios anticoagulantes para obtener PRP en bovinos. Es importante realizar futuras investigaciones para conocer las concentraciones de factores de crecimiento liberados por las plaquetas bovinas luego de la activación con sustancias tales como las sales de calcio o la trombina y las condiciones óptimas para obtener PRP libre de bacterias (Álvarez y col 2010). También, es apremiante saber si el protocolo utilizado en este estudio se puede aplicar de igual forma en bovinos Bos indicus. Finalmente, es necesario iniciar estudios clínicos en bovinos que demuestren la utilidad terapéutica de esta sustancia.

\section{RESUMEN}

El objetivo de este estudio fue evaluar un método de centrifugado doble en tubo para concentrar plaquetas bovinas. Muestras de sangre fueron recolectadas de vacas Holstein clínicamente normales y procesadas por un método de centrifugación doble en tubo para obtener plasma rico en plaquetas (PRP). El PRP y la sangre entera fueron analizados por un sistema de impedancia volumétrica para hemograma y parámetros plaquetarios adicionales (volumen plaquetario medio (VPM) y ancho de distribución del volumen de plaquetas (PDW). Las concentraciones de plaquetas en el PRP fueron 129\% mayores en comparación con la concentración de plaquetas de la sangre entera. Se observaron correlaciones significativas positivas entre las concentraciones de plaquetas y linfocitos $(\rho=0,81, \mathrm{P}=0,0001)$, plaquetas y leucocitos $(\rho=0,75, \mathrm{P}=0,0001)$ y una correlación negativa significativa entre el conteo de plaquetas y PDW ( $\rho=-0,72, P=0,0001)$. En conclusión, el método de centrifugación doble en tubo evaluado en este estudio es confiable para la producción PRP en bovinos.

\section{AGRADECIMIENTOS}

Los autores agradecen a Diana L. Ríos, John J. Borbón, Juan S. Gutiérrez y Néstor A. Villa.

\section{REFERENCIAS}

Álvarez ME, CE Giraldo, JU Carmona. 2010. Bacterial contamination in platelet concentrates of horses. Arch Med Vet 42, 49-56.

Álvarez ME, C López, CE Giraldo, I Samudio, JU Carmona. 2011. In vitro bactericidal activity of equine platelet concentrates, platelet poor plasma, and plasma against methicillin-resistant Staphylococcus aureus. Arch Med Vet 43, 155-161.

Anitua E. 1999. Plasma rich in growth factors: Preliminary results of use in the preparation of future sites for implants. Int J Oral Maxillofac Implants 14, 529-535.

Argüelles D, JU Carmona, J Pastor, A Iborra, L Viñals, P Martínez, E Bach, M Prades. 2006. Evaluation of single and double centrifugation tube methods for concentrating equine platelets. Res Vet Sci 81, 237-245.

Carmona JU, D Arguelles, M Prades. 2008. Transforming growth factor beta-3 and nitric oxide levels in four autologous platelet concentrates and plasma derived from equine blood. Arch Med Vet 40, 155-160.

Carmona JU, C López, M Prades. 2009ª Use of autologous platelet concentrates obtained by the tube method as a treatment for arthropathies in horses. Arch Med Vet 41, 175-179.

Carmona JU, M Prades, D Arguelles. 2009 ${ }^{\mathrm{b}}$. Autologous platelet concentrates as a treatment for soft tissue musculoskeletal lesions in horses. Arch Med Vet 41, 77-82.

Carmona JU, C López, CE Giraldo. 2011. Use of autologous platelet concentrates as regenerative therapy for chronic diseases of the equine musculoskeletal system. Arch Med Vet 43, 1-10.

Dohan Ehrenfest DM, L Rasmusson, T Albrektsson. 2009. Classification of platelet concentrates: from pure platelet-rich plasma (P-PRP) to leucocyte- and platelet-rich fibrin (L-PRF). Trends Biotechnol 27, 158-167.

Dohmen MJW, K Joop, A Sturk, PEJ Bols, JACM Lohuis. 2000. Relationship between intra-uterine bacterial contamination, endotoxin levels and the development of endometritis in postpartum cows with dystocia or retained placenta. Theriogenology 54, 1019-1032.

Eppley BL, JE Woodell, J Higgins. 2004. Platelet Quantification and Growth Factor Analysis from Platelet-Rich Plasma: Implications for Wound Healing. Plast Reconstr Surg 114, 1502-1508.

Fréchette J-P, I Martineau, G Gagnon. 2005. Platelet-rich Plasmas: Growth Factor Content and Roles in Wound Healing. J Dent Res 84, 434-439.

Heppelmann M, J Kofler, H Meyer, J Rehage, A Starke. 2009. Advances in surgical treatment of septic arthritis of the distal interphalangeal joint in cattle: A review. Vet $J$ 182, 162-175.

Lee WS, TY Kim. 2010. Mean platelet volume and platelet distribution width are useful in the differential diagnosis of aplastic anemia and idiopathic thrombocytopenic purpura. Clin Chem Lab Med 48, 1675-1676.

López C, JU Carmona, I Samudio. 2010. Use of autologous platelet concentrates as treatment for a scapular fracture and brachial 
plexus nerve injury produced by a gunshot in a horse. Arch Med Vet 42, 209-214.

Marx RE, ER Carlson, RM Eichstaedt, SR Schimmele, JE Strauss, KR Georgeff. 1998. Platelet-rich plasma: Growth factor enhancement for bone grafts. Oral Surg Oral Med Oral Pathol Oral Radiol Endod 85, 638-646.

Roukis T, T Zgonis, B Tiernan. 2006. Autologous platelet-rich plasma for wound and osseous healing: A review of the literature and commercially available products. Adv Ther 23, 218-237.

Searcy GP, D Sheridan, KA Dobson. 1990. Preliminary studies of a platelet function disorder in Simmental cattle. Can J Vet Res 54, 394-396.

Silva RF, CMF Rezende, JU Carmona. 2011 a . Evaluación del método del tubo para concentrar plaquetas felinas: estudio celular. Arch Med Vet 43, 187-190.

Silva RF, CMF Rezende, JU Carmona. 2011 ${ }^{\mathrm{b}}$. Uso de concentrados autólogos de plaquetas intraarticulares como coadyuvantes en el tratamiento quirúrgico de la rotura del ligamento cruzado anterior en una perra. Arch Med Vet 43, 313-316.

Silva RF, CMF Rezende, FO Paes-Leme, JU Carmona. 2011c. Evaluación del método del tubo para concentrar plaquetas caninas: estudio celular. Arch Med Vet 43, 95-98.

Thoesen MS, WSV Berg-Foels, T Stokol, KM Rassnick, MS Jacobson, SV Kevy, RJ Todhunter. 2006. Use of a centrifugation-based, pointof-care device for production of canine autologous bone marrow and platelet concentrates. Am J Vet Res 67, 1655-1661.

Weibrich G, WKG Kleis, WE Hitzler, G Hafner. 2005. Comparison of the platelet concentrate collection system with the plasma-richin-growth-factors kit to produce platelet-rich plasma: A technical report. Int J Oral Maxillofac Implants 20, 118-123.

Wittek T, M Fürll, PD Constable. 2004. Prevalence of endotoxemia in healthy postparturient dairy cows and cows with abomasal volvulus or left displaced abomasum. $J$ Vet Intern Med 18, 574-580. 